PACS: 61.05.cf, 61.05.cp, 61.41.+e, 61.43.-j

\title{
PROCESSES OCCURRING IN THE POLYIMIDE FILMS PM-A (AS KAPTON H) DURING THE DEFORMATION AND COOLING
}

\author{
I.S. Braude, V.G. Geidarov, Yu.M. Pogribnaya \\ B. Verkin Institute for Low Temperature Physics and Engineering of the National Academy of Sciences of Ukraine \\ 47 Nauky Ave., 61103, Kharkiv, Ukraine \\ e-mail: geydarov@ilt.kharkov.ua \\ Received March 18, 2018
}

The evolution of the film structure of polyimide PM-A (Kapton $\mathrm{H}$ type) after deformation at $\mathrm{T}=300 \mathrm{~K}$, the effect of low temperatures and subsequent deformation at liquid nitrogen and liquid helium temperatures is studied. Particular attention is paid to comparative analysis of structural changes in the process of various external influences. The starting material was a film synthesized from solutions of prepolymers with a thickness of $0.08 \mathrm{~mm}$. Part of the samples were subjected to a successively of temperature deformation and uniaxial deformation. For the original samples, we observed a symmetrical halo on the x-ray diffraction pattern on the small angles. The cooling of the polyimide film at $\mathrm{T}=77 \mathrm{~K} 4.2 \mathrm{~K}$ leads to the appearance of an additional peak in the region of smaller angles. The deformation of the sample at room temperature leads to the appearance of an additional peak in the region of large angles. Low-temperature deformation at temperatures of liquid nitrogen and liquid helium affects the structural state of the samples in different ways. Proposed two "mechanism", which are qualitatively, describe the processes in this polyimide films after deformation at low temperatures. It is assumed that as a result of cooling, "bundles" are formed, consisting of a different number of polymer segments. Low-temperature deformation at $77 \mathrm{~K}$ and $4.2 \mathrm{~K}$, respectively, leads to compression and rupture of these bundles. KEYWORDS: polyimide, deformation, X-ray diffractometry, ordering

\section{ПРОЦЕСИ, ЯКІ ВІДБУВАЮТЬСЯ У ПЛІВКАХ ПОЛІМІДА ПМ-А (тИПУ Кapton Н) ПРИ ДЕФОРМАЦІЇ І ОХОЛОДЖЕННІ \\ І.С. Брауде, В.Г. Гейдаров , Ю.М. Погрібиа \\ Фізико-технічний інститут низьких температур ім. Б.І. Вєркіна НАНУ} пр. Науки 47, 61103 Харків, Украӥна

В роботі вивчено еволюцію структури плівки полііміда ПМ-А (типу Kapton Н) після деформації при Т = 300К, впливу низьких температур і подальшої деформації при температурах рідкого азоту і рідкого гелію. Особлива увага в роботі приділена порівняльному аналізу змін структури в процесі різних зовнішніх впливів. Вихідним матеріалом служила плівка, синтезована з розчинів форполимера товщиною 0,08 мм. Частина зразків була піддана послідовно температурній деформації і одноосьовій деформації. На дифрактограмі спостерігається широкий пік (гало) тільки на малих кутах. Охолодження зразка (температурна деформація) до $\mathrm{T}=77 \mathrm{~K}, \mathrm{~T}=4,2 \mathrm{~K}$ тягне за собою появу додаткового піку з боку малих кутів. Однак, деформація при $\mathrm{T}=300 \mathrm{~K}$ призводить до появи додаткового максимуму 3 боку більших кутів. Низькотемпературна деформація при температурах рідкого азоту і рідкого гелію по-різному впливає на структурний стан зразків. Наведено два можливих механізми зміни структури в результаті спільного впливу деформації і низьких температур. Передбачається, що в результаті охолодження утворюються «джгути», що складаються 3 різної кількості полімерних сегментів. Низькотемпературна деформація при 77К і 4,2К призводить, відповідно, до стиснення і розриву цих джгутів.

КЛЮЧОВІ СЛОВА: поліімід, деформація, рентгенівська дифрактометрія, впорядкування

\section{ПРОЦЕССЫ, ПРОТЕКАЮЩИЕ В ПЛЕНКАХ ПОЛИИМИДА ПМ-А (ТИПа Каpton Н) ПРИ ДЕФОРМАЦИИ И ОХЛАЖДЕНИИ \\ И.С. Брауде, В.Г. Гейдаров, Ю.М. Погрибная}

Физико-технический институт низких температур им. Б.И. Веркина НАНУ пр. Науки 47, 61103 Харьков, Украина

В работе изучена эволюция структуры пленки полиимида ПМ-А (типа Kapton H) после деформации при Т=300К, воздействия низких температур и последующей деформации при температурах жидкого азота и жидкого гелия. Особое внимание в работе уделено сравнительному анализу изменений структуры в процессе различных внешних воздействий. Исходным материалом служила пленка, синтезированная из растворов форполимеров толщиной 0,08 мм. Часть образцов были подвергнуты последовательно температурной деформации и одноосной деформации. На дифрактограмме наблюдается широкий пик (гало) только на малых углах. Охлаждение образца (температурная деформация) до Т=77К, $\mathrm{T}=4,2 \mathrm{~K}$ влечет за собой появление дополнительного пика со стороны малых углов. Однако, деформация при $\mathrm{T}=300 \mathrm{~K}$ приводит к появлению дополнительного максимума со стороны бо́льших углов. Низкотемпературная деформация при температурах жидкого азота и жидкого гелия по-разному влияет на структурное состояние образцов. Приведены два возможных механизма изменения структуры в результате совместного воздействия деформации и низких температур. Предполагается, что в результате охлаждения образуются «жгуты», состоящие из разного количества полимерных сегментов. Низкотемпературная деформация при 77К и 4,2К приводит, соответственно, к сжатию и разрыву этих жгутов. КЛЮЧЕВЫЕ СЛОВА: полиимид, деформация, рентгеновская дифрактометрия, упорядочение

Твердотельные полимеры - это соединения, у которых взаимодействие внутри молекулы намного больше, чем между молекулами [1]. К этой же группе веществ относятся молекулярные криокристаллы [2] и новые 
углеродные материалы (фуллерены, нанотрубки и графены) [3,4]. Полиимид - это разновидность полимеров, состоящая из цепочечных макромолекул (рис. 1)[1].

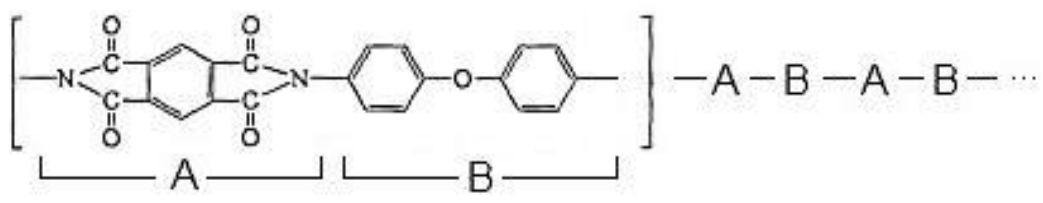

Рис. 1 Молекула полиимида ПМ-А

Особенности упорядочения, характерные для молекулярных соединений, обладающих только ближним порядком, ярко проявляются в углеродных нанотрубках [5]. Технология получения одиночных одностенных углеродных нанотрубок заключается в следующем. Жгуты нанотрубок «разбивают» ультразвуком и «наматывают» на них «изолятор» (поверхностно активное вещество, ДНК или др.) [6,7]. После удаления «изолятора» углеродные нанотрубки «слипались», образовывая новые связки, по размеру отличающиеся от исходных, то есть происходит взаимное упорядочение молекул. Такое поведение при взаимном упорядочении (образование жгутов) объясняется Ван-дер-Ваальсовым взаимодействием между углеродными одностенными нанотрубками (молекулами). Другой пример упорядочения нанотрубок наблюдался в [5]. В этой работе образец, состоящий из нанотрубок, подвергался одноосному растяжению. На дифракционной картине при этом возникали «дополнительные» широкие максимумы, появление которых авторы связывают с выстраиванием (упорядочением) некоторой части молекул (нанотрубок) вдоль оси приложения силы.

Целью данной работы является изучение процессов, протекающих в пленках полиимида ПМ-А (типа Kapton H), в результате внешнего воздействия - выдерживании при низких температурах $(77 \mathrm{~K}$ и 4,2К) и одноосной деформации.

\section{ОБЪЕКТЫ И МЕТОДИКА ЭКСПЕРИМЕНТА}

В работе исходным материалом служила пленка ПМ-А, синтезированная из растворов форполимеров [1]. Из пленки были вырезаны образцы в форме полосок размерами $70 \times 5 \times 0,08 \mathrm{~mm}^{3}$.

Часть образцов были подвергнуты последовательно температурной деформации и одноосной деформации. Температурная деформация осуществлялась путем выдерживания заготовок в течение трёх часов в азоте или гелии. Одноосную деформацию образцов осуществляли в режиме ползучести путем ступенчатого нагружения при температурах 293К, 77К и 4,2К [8,9].

Рентгеноструктурные исследования исходных и деформированных пленок полиимида ПМ-А производили на дифрактометре ДРОН-2.0 в $\mathrm{K}_{\alpha}$ излучении медного анода с никелевым фильтром, с системой коллимационных щелей и с последующей компьютерной обработкой данных. Съемку осуществляли при комнатной температуре в интервале углов $2 \theta=4-70^{\circ}$. Следует отметить, что все съёмки дифрактограмм проводились сразу же после воздействия на них различных факторов. Авторы при этом предполагают, что образец в процессе отогрева до комнатной температуры сохраняет структуру, которая была сформирована в результате воздействия низких температур и/или деформации. Дифракционные профили полученных кривых аппроксимировали колокообразными функциями (Гаусс) с помощью математической программы.

\section{РЕЗУЛЬТАТЫ И ОБСУЖДЕНИЕ}

На дифрактограмме для исходного образца (рис. 2) наблюдается симметричный широкий пик (гало) на малых углах. Это является свидетельством отсутствия в образце дальнего порядка и наличие ближнего порядка.

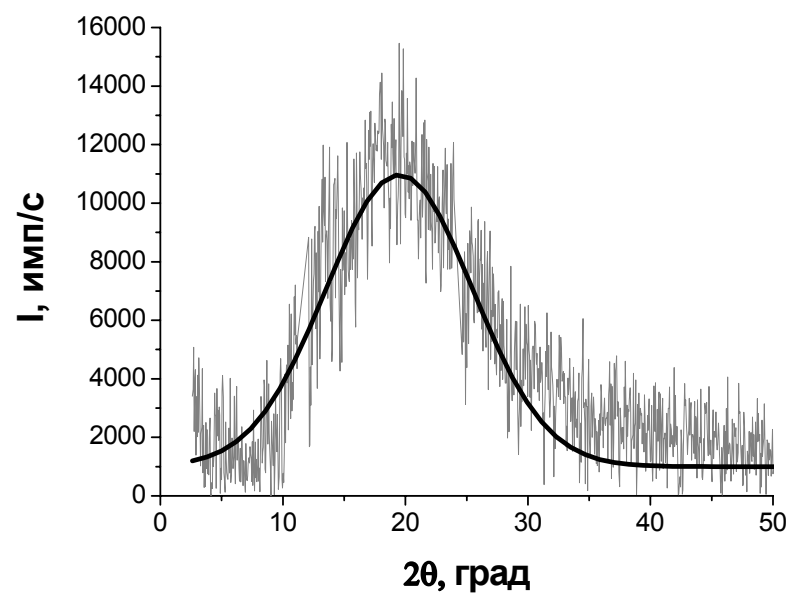

Рис. 2. Зависимость интенсивности рассеяния от угла сканирования для исходной плёнки 
То есть исследуемый образец, с точки зрения трансляционного порядка, является аморфным. Отсутствие кристаллической фазы может быть обусловлено активно протекающими релаксационными процессами (вылеживание) при комнатной температуре $[10,11]$ на протяжении около 30 лет (год производства исследуемой пленки 1988-1989 гг). Охлаждение полиимидной пленки (температурная деформация) при Т=77К (рис. 3a) приводит к появлению дополнительного пика в области меньших углов. Такой вид дифрактограммы может свидетельствовать об образовании областей ближнего порядка с различными размерами: как в исходном состоянии, так и с меньшими размерами, т.е. появляются области сжатия. Появление дополнительного максимума можно объяснить тем, что в процессе охлаждения происходит «слипание» (упорядочение молекул друг относительно друга) какой-то части макромолекул с образованием некого подобия связок углеродных нанотрубок [6,7]. Аналогичная картина наблюдается при охлаждение полиимидной пленки (температурная деформация) при $\mathrm{T}=4,2 \mathrm{~K}$ (рис. 3б).

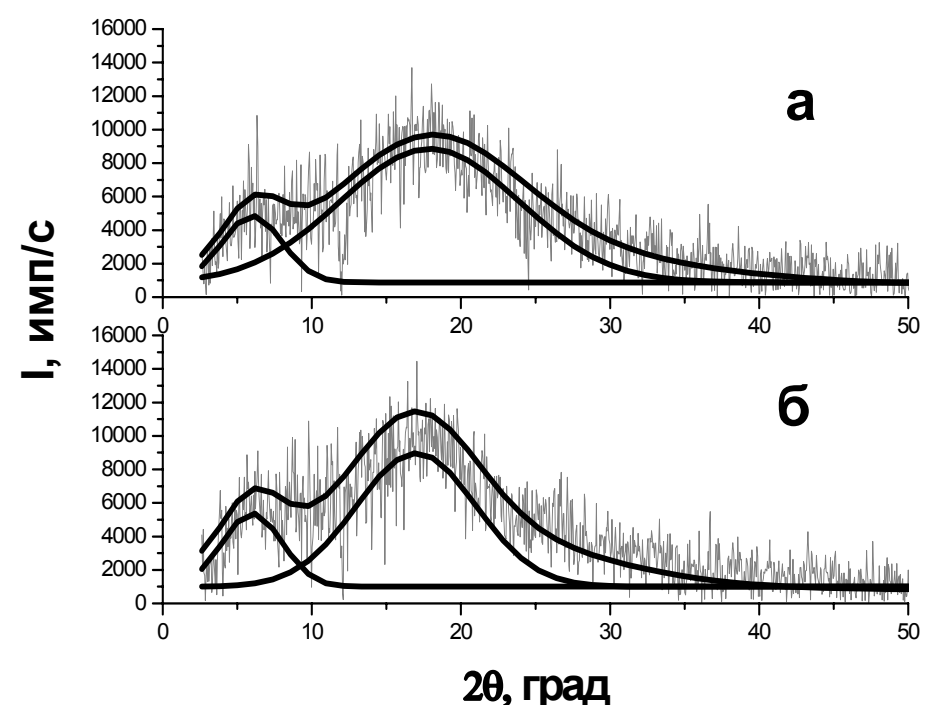

Рис. 3. Зависимость интенсивности рассеяния от угла сканирования для пленки, охлажденной при а) $\mathrm{T}=77 \mathrm{~K}$; б) $\mathrm{T}=4,2 \mathrm{~K}$

Деформация при комнатной температуре также приводит к появлению дополнительного пика (рис. 4), но в области бо́льших углов, как и в работе [12]. Это говорит о том, что в деформированном образце при комнатной температуре, происходит формирование областей ближнего порядка с бо́льшим размером, нежели в исходном образце, и в образцах, охлажденных при низких температурах. Аналогичное поведение наблюдалось в уже вышеупомянутой работе [5] при изучении нанотрубок, подвергавшихся одноосному растяжению. В этой работе авторы связывают возникновение «дополнительных» широких максимумов с тем, что при одноосной деформации некоторой части молекул (нанотрубок) выстраиваются (упорядочиваются) вдоль оси приложения силы.

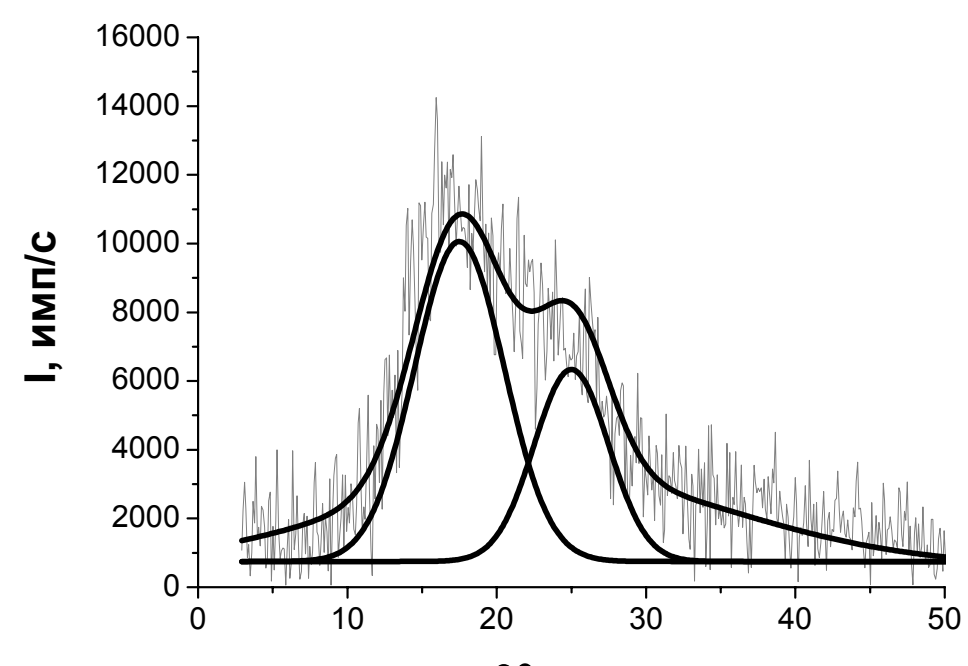

20, град

Рис.4. Зависимость интенсивности рассеяния от угла сканирования для пленки, деформированной при комнатной температуре 
Низкотемпературная деформация при $\mathrm{T}=77 \mathrm{~K}$ приводит к тому, что на дифрактограмме (рис. 5а) наблюдается, как и при «чистом охлаждении», два широких пика («основной» и «дополнительный»). Качественно другая картина наблюдается при низкотемпературной деформации при $\mathrm{T}=4,2 \mathrm{~K}$. На дифрактограмме при этом (рис. 5б) наблюдается только симметричное гало, как и для исходного образца (рис. 2).

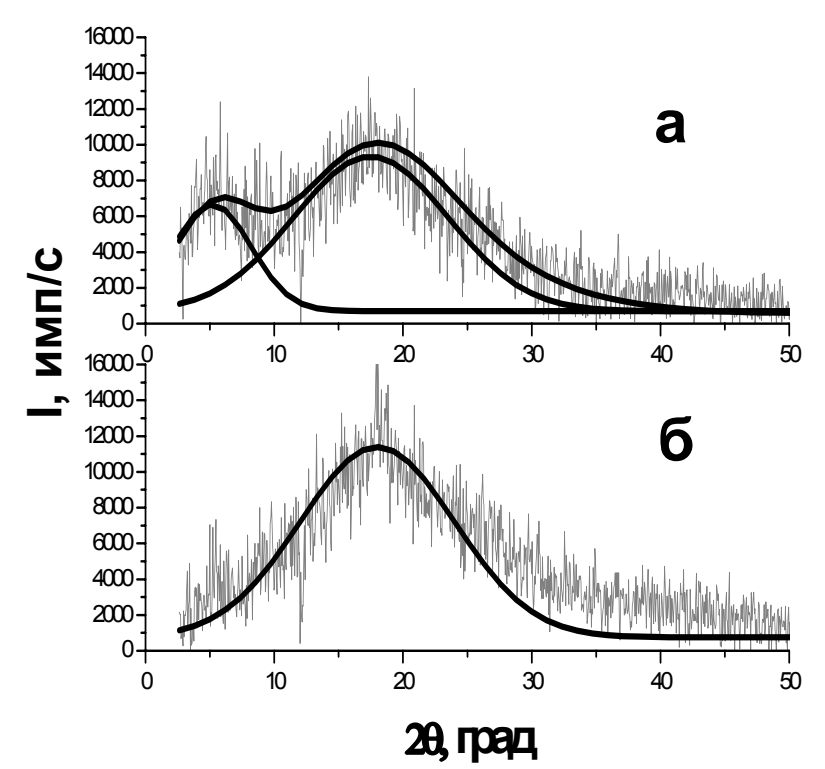

Рис. 5. Зависимости интенсивностей рассеяния от угла сканирования для пленки, деформированной при а) 77 К; б) 4,2 К

Такое поведение можно объяснить следующими двумя процессами, происходящими в образцах:

Во-первых: образцы охлаждались с большой скоростью (порядка $100 \mathrm{~K} /$ мин), т.е. в них происходило подобие «закалки». В результате этого образовавшиеся при криовоздействии «жгуты» состоят из разного количества полимерных цепей (в зависимости от скорости «закалки»), а следовательно, имеют разную жесткость. Значит, для «разбития» жгутов полученных при разных температурах, необходимо прикладывать разное усилие. Этим можно объяснить полученное различие на дифрактограммах на рис. 5. В итоге при азотной температуре в результате приложенных усилий дополнительный максимум смещается в сторону малых углов (рис. 5a), а при гелиевых температурах максимум становится симметричным (рис. 5б).

Во-вторых: различие на дифрактограммах на рис. 5 может быть получено вследствие того, что под действием внешней нагрузки при гелиевой температуре «жгуты», состоящие из полимерных цепей, уменьшаются по длине (попросту ломаются). Это приводит к тому, что «жгуты» хаотично разориентируются друг относительно друга.

\section{ВЫВОДЫ}

1. Проведены рентгеноструктурные исследования полиимидных пленок ПМ-А, подвергнутых криоохлаждению и одноосному растяжению при температурах 300 К, 77 К и 4,2 К.

2. Предполагается, что в результате охлаждения до низких температур происходит взаимное упорядочение части молекул и это проявляется в виде появления дополнительного пика в области меньших углов.

3. В результате одноосной деформации пленки при $300 \mathrm{~K}$ происходит частичная ориентация (выстраивание) молекул в направлении приложенной нагрузки, что на дифрактограммах проявляется в виде смещения дополнительного пика в сторону бо́льших углов.

4. Приведены два возможных механизма изменения структуры в результате низкотемпературной деформации. Предполагается, что в результате охлаждения образуются «жгуты», состоящие из разного количества полимерных сегментов. Низкотемпературная деформация при 77К и 4,2К приводит, соответственно, к сжатию и разрыву этих жгутов.

Авторы благодарят В.Д. Нацика за прочтение текста и сделанные ценные замечания.

\section{СПИСОК ЛИТЕРАТУРЫ}

1. Bessonov M.I., Koton M.M., Kudryavtsev V.V., Lajus L.A. Poliimidy - klass termostojkih polimerov [Polyimides - a class of heat-resistant polymers]. - Leningrad: Nauka, 1988. (in Russian) 
2. Manzhelii V.G., Freiman Yu.A. Physics of Cryocrystals. - Woodbury, New York: AIP Press, 1996.

3. Kroto H.W., Heath J.R., O'brien S.C., Curl R.F., Smalley R.E. C 60 : Buckminsterfullerene // Nature. - 1985. - Vol.318. - P.162; doi:10.1038/318162a0

4. Iijima S. Helical microtubules of graphitic carbon // Nature. - 1991. - Vol. 354. - P. 56; doi:10.1038/354056a0

5. Jin L., Bower C., Zhou O. Alignment of carbon nanotubes in a polymer matrix by mechanical stretching // Appl. Phys. Lett.1998. - Vol. 73. - P. 1197, http://dx.doi.org/10.1063/1.122125

6. O'Connell M.J., Bachilo S.M, Huffman C.B., Moore V.C., Strano M.S., Haroz E.H., Rialon K.L., Boul P.J., Noon W.H., Kittrell C., Ma J., Hauge R.H., Weisman R.B., Smalley R.E. Band gap fluorescence from individual single-walled carbon nanotubes // Science. - 2002. - Vol. 297. - P. 593, doi:10.1126/science.1072631

7. Karachevtsev V.A., Plokhotnichenko A.M., Glamazda A.Yu., Leontiev V.S., Levitsky I.A. Excitonic energy transfer in polymer wrapped carbon nanotubes in gradually grown nanoassemblies // Phys. Chem. Chem. Phys. - 2014. - Vol. 16. P. 10914, doi:10.1039/C4CP00776J

8. Zinov'yev M.V., Koval' V.A., Danilenko L.I., Soldatov V.P. Ustanovka dlya izucheniya protsessa nizkotemperaturnoy polzuchesti [Installation for studying the low-temperature creep process] // Strength problems. - 1970. - No.6. - P.92. (in Russian)

9. Soldatov V.P., Kirichenko G.I., Abraimov V.V., Braude I.S., Geidarov V.G. The laws of deformation of an amorphous polyimide (PI) film when it is stretched in the temperature range 1.6-300 K // Low Temp. Phys. - 2016. - Vol. 42. - P. 817, doi:10.1063/1.4963917

10. Kargin V.A., Slonimskiy G.L. Kratkiye ocherki po fiziko-khimii polimerov [Brief essays on the physicochemistry of polymers] - M.: Chemistry, 1967. - 232 p. (in Russian)

11. Lototskaya V.A., Yakovenko L.F., Aleksenko E.N., Abraimov V.V., Wen Zhu Shao Low temperature deformation and strength of polyimide films due to thickness and deformation speed // East. Eur. J. Phys. - 2017. - Vol.4. - No.2. - P.44-52.

12. Braude I.S., Gal'tsov N.N., Geidarov V.G., Kirichenko G.I., Abraimov V.V. Effect of deformation and temperature on the ordering of polyimide PM-A molecules. X-ray data // Low Temp. Phys. - 2016. - Vol. 42. - P. 204, doi:10.1063/1.4944734 